\title{
Myocardial infarction in diabetic rats: role of hyperglycaemia on infarct size and early expression of hypoxia-inducible factor 1
}

\author{
R. Marfella ${ }^{1,3,4}$, M. D’Amico ${ }^{2,3}$, C. Di Filippo ${ }^{2,3}$, E. Piegari², F. Nappo ${ }^{1}$, K. Esposito ${ }^{1}$, L. Berrino ${ }^{2,3}$, F. Rossi ${ }^{2,3}$, \\ D. Giugliano ${ }^{1,3}$ \\ ${ }^{1}$ Department of Geriatrics and Metabolic Diseases, Second University of Naples, Naples, Italy \\ ${ }^{2}$ Department of Experimental Medicine, Second University of Naples, Naples, Italy \\ 3 "Centro di Eccellenza Cardiovascolare", Second University of Naples, Naples, Italy \\ 4 Via Emilio Scaglione 141, 80145 Napoli, Italy
}

\section{Abstract}

Aims/hypothesis. This study aimed to evaluate the effects of hyperglycaemia on the evolution of myocardial infarction and the expression of the transcriptional factor for angiogenesis hypoxia-inducible factor $1 \alpha$ $(\mathrm{HIF}-1 \alpha)$ in the rat.

Methods. We studied the effects of streptozotocin induced diabetes on infarct size and HIF-l $\alpha$ gene expression. These parameters were also evaluated in isolated hearts of non-diabetic rat, in condition of high glucose concentration.

Results. In streptozotocin (STZ)-diabetic rats (in vivo study), myocardial infarct size was greater $(p<0.01)$ in hyperglycaemic rats $(22 \mathrm{mmol} / \mathrm{l})$ than in normoglycaemic $(7 \mathrm{mmol} / \mathrm{l})$ or non-diabetic rats. In euglycaemic conditions, basal expression of HIF- $1 \alpha$ mRNA was not appreciable, but increased steadily after ischaemia $(762 \pm 86 \%, p<0.001)$; this response was blunted in hyperglycaemic STZ-rats $(6.8 \pm 6 \%$ of the control, $p<0.001)$ and improved in euglycaemic STZ-rats $(58 \pm 10 \%)$. The changes in myocardial Rac1
mRNA expression paralleled those of HIF-1 $\alpha$. In isolated hearts from non-diabetic rats (in vitro study), perfusion with high glucose $(33 \mathrm{mmol} / \mathrm{l})$ produced an infarct size $(58 \pm 2 \%$ of the area at risk) not different from that obtained in hyperglycaemic STZ-rats $(57 \pm 2 \%)$. Similar changes in the expression of HIF$1 \alpha$ and Rac1, which were prevented by glutathione infusion $(0.3 \mathrm{mmol} / \mathrm{l})$ were also observed.

Conclusion/interpretation. Both hyperglycaemia and high glucose concentrations increased basal HIF- $1 \alpha$ and Rac1 expression, suggesting a state of pseudohypoxia. These findings show that myocardial infarct size in the rat is increased in hyperglycaemic conditions and is associated with a reduced expression of the HIF-1 $\alpha$ gene. These changes are reversed, totally or partially, by normoglycaemia or glutathione suggesting a role for reactive oxygen species generation brought about by hyperglycaemia. [Diabetologia (2002) 45:1172-1181]

Keywords Streptozotocin diabetes, isolated heart, infarct size, hyperglycaemia, $\mathrm{H} 1 \mathrm{~F}-1 \alpha$.
Received: 24 January 2002 / Revised: 10 April 2002

Published online: 26 June 2002

(C) Springer-Verlag 2002

R. Marfella and M. D'Amico share first authorship

Corresponding author: R. Marfella, Department of Geriatrics and Metabolic Diseases, Second University of Naples, Naples, Italy. E-mail: raffaele.marfella@unina2.it

Abbreviations: CPP, Coronary perfusion pressure; GGC, good glycaemic control; HIF-1 $\alpha$, hypoxia-inducible factor $1 \alpha$; HR, heart rate; HG, high glucose; IS, infarct size; LADCA, left anterior descending coronary artery; LV, left ventricle; MABP, mean arterial blood pressure; NBT, intro-blue-tetrazolium; NG, normal glucose; PGC, poor glycaemia control; STZ, steptozotocin.
An unusually high prevalence of glycosuria in patients without diabetes who have acute myocardial infarction was noted as far back as 1931 [1]. Stress hyperglycaemia after myocardial infarction is associated with an increased risk of in-hospital mortality in patients with and without diabetes [2]. Moreover, a positive association between hyperglycaemia at the time of the event and subsequent mortality from myocardial infarction has been reported [3]. Although the mechanisms underlying this association are not fully understood, evidence that the use of insulin to lower glucose concentrations decreases mortality in patients with diabetes who have myocardial infarction [4] suggests that hyperglycaemia is not simply an epiphe- 
nomenon of a stress response. Consequently, hyperglycaemia at the time of myocardial infarction could be an important and potentially modifiable risk factor for poor outcome.

Hypoxia, subsequent to ischaemia, is a potent regulator of a variety of biologic processes, including angiogenesis, vascular contractility, and erythropoiesis [5]. Hypoxia-inducible factor $1 \mathrm{a}(\mathrm{HIF}-1 \alpha)$ is a transcriptional factor that is expressed in response to a decrease in the partial pressure of cellular oxygen and activates genes involved in angiogenesis, glycolysis, modulation of vascular tone, and erythropoiesis $[6,7]$. Several studies have found increased expression of HIF- $\alpha$ messenger RNA (mRNA) in hypoxic cultured cells and in organs (the retina and the lung) of animals exposed to short-term or long-term hypoxia [8, 9]. Moreover, an early increase in the cardiac expression of HIF- $1 \alpha$ has been observed in response to myocardial ischaemia or infarction in humans [10].

This study examined whether the evolution of myocardial ischaemia and infarction is influenced by diabetes. We examined infarct size, HIF- $1 \alpha$ expression, and Rac 1 expression, a small GTPase involved in HIF- $1 \alpha$ response to ischaemia [11], in heart tissue of rats with streptozotocin-induced diabetes. In order to dissect the role of hyperglycaemia per se on the evolution of myocardial injury, infarct size, HIF- $1 \alpha$ and Rac 1, myocardial expression were evaluated in isolated working hearts of non-diabetic rats perfused with high glucose. The role of reactive oxygen species in mediating the effects of hyperglycaemia was assessed with glutathione, a powerful antioxidant. The results are consistent with an effect of hyperglycaemia to increase infarct size, and reduce the transcriptional angiogenetic response to ischaemia in the rat.

\section{Materials and methods}

Experimental protocol. All of our experimental procedures and protocols were reviewed and approved by the Animal Care and Use Committee of the Medical College of Naples. Two separate ischaemia-reperfusion studies were carried out. In the in vivo study, rats were randomly allocated to one of the three following groups: non-diabetic rats (10 sham operated rats; 10 infarcted rats); streptozotocin (STZ) rats in poor glycaemic control (PGC rats, 10 sham operated rats; 10 infarcted rats); STZ rats in good glycaemic control (GGC rats, 10 sham operated rats; 10 infarcted rats). In the in vitro study, excised rat hearts were perfused with normal glucose solution (control, 10 sham operated hearts; 10 infarcted hearts), high glucose solution (10 sham operated hearts, 10 infarcted hearts), high glucose solution plus glutathione (10 sham operated hearts, 10 infarcted hearts). Normal glucose solution plus glutathione were perfused in four hearts to ascertain whether glutathione perfusion could modify infarct size. To evaluate the effect of the osmotic solution per se, six hearts were perfused with a buffer solution containing normal glucose solution plus mannitol.

In vivo ischaemia-reperfusion injury. Experiments were carried out in 40 male Sprague-Dawley rats (4-6 months old and weighing on average $250 \mathrm{~g}$ ). Under sodium pentobarbital anaesthesia (50 mg/kg i.p.) and aseptic conditions, a catheter was inserted into the femoral vein. This was passed subcutaneously and exteriorised on the back of the neck. Incisions were infiltrated with penicillin $\mathrm{G}$ procaine $(300000 \mathrm{IU} / \mathrm{ml})$ and bupivacaine $(11.25 \%)$ at closure. The venous catheter was connected to a syringe pump (Harvard Apparatus, Edenbridge, Kent, UK) that ran continuously throughout the study. All solutions contained antibiotic (25000 IU penicillin G/rat per day and $0.03 \mathrm{~g}$ mezeocillin/rat per day) and were infused through a Millipore filter (0.22-mm, Cathivex, Millipore, Bedford, Mass., USA). Streptozotocin $(70 \mathrm{mg} / \mathrm{kg}$ i.v) was administered at 16:00 hours through a venous catheter. In the morning of the next day, $15 \mathrm{~h}$ later, the venous catheter was connected to a syringe pump (Harvard Apparatus) and a continuous intravenous infusion of regular insulin $(1.5 \pm 0.5 \mathrm{U} /$ day $)$ was begun and adjusted to yield blood glucose concentrations of approximately $22 \mathrm{mmol} / \mathrm{l}(396 \mathrm{mg} / \mathrm{dl}$ ) for 8 days (PGC rats, $n=20)$. In GGC rats $(n=20)$, the insulin dose was increased to $4 \mathrm{U} /$ day to obtain and maintain normoglycaemia for the subsequent 8 days. The other 20 rats served as non-diabetic controls and underwent the same surgical procedures, including the iv catheter, as diabetic rats. Plasma glucose concentration was measured daily with an Accutrend II glucose analyser (Roche Diagnostics, Monza, Italy) using approximately $50 \mu \mathrm{l}$ of blood from the venous catheter.

The surgical procedure has been described [12]. In brief, rats were anaesthetised with urethane $(120 \mathrm{mg} / \mathrm{kg}$ i.p. $)$ and prepared for coronary artery. The left jugular vein was cannulated to allow administration of further anaesthetic and drugs; a tracheotomy was done using a polythene cannula to permit artificial ventilation when required; and the right carotid artery was cannulated for blood pressure measurement. A left thoracotomy was done (between the fourth and the fifth ribs approximately $3 \mathrm{~mm}$ from the sternum) and the pericardium removed to expose the heart. The heart was exteriorised and a fine silk ligature (attached to a $10 \mathrm{~mm}$ micropoint reverse cutting needle) (Ethicon W593 6/0, Pomezia, Roma, Italy) was placed around the left anterior descending coronary artery (LADCA) close to its origin. Rats were kept under artificial ventilation (Rodent Ventilator, Basile. Comeno, VA, Italy) with room air at a rate of 54 strokes $\cdot \mathrm{min}^{-1}$, a stroke volume of 1.0 to $1.5 \mathrm{ml}$ $100 \mathrm{~g}^{-1}$ and a positive end expiratory pressure of 0.5 to $1 \mathrm{~cm}$ $\mathrm{H}_{2} \mathrm{O}$. This was sufficient to maintain $\mathrm{PCO}_{2}$ at $18-24 \mathrm{mmHg}$, $P_{2}$ at $100-130 \mathrm{mmHg}$, and a $\mathrm{pH}$ within normal limits of 7.4 units.

A lead-I electrocardiogram was monitored from subcutaneous stainless steel electrodes. Both the ECG and the mean arterial blood pressure (MABP) were continuously recorded by a Statham Spectramed pressure transducer connected to a Gould polygraph (Gould RS 3400, Hainault, Ilford, Essex, UK). The heart rate (HR) was measured by ECG. A rectal thermometer was inserted and the rats were kept at a body temperature of 37 to $38^{\circ} \mathrm{C}$ by a homeothermic blanket.

After the surgical procedure was completed the animals were allowed to stabilize for $30 \mathrm{~min}$ before coronary artery occlusion. Both ends of the ligature around the coronary artery were threaded through a small polythene button which was placed in contact with the heart. Coronary artery occlusion was achieved by applying tension to it and clamping the ligature against the button with a small, light weight, rubber-sheathed artery clip. This was associated with the typical electrocardiographic (ST-segment elevation and increase in R-wave amplitude) and haemodynamic changes (fall in mean arterial blood pressure) of myocardial ischaemia. After 25 min of myocardial ischaemia the clip was removed so that the tension on the ligature was released and reperfusion was allowed for $2 \mathrm{~h}$. 
Two hours after the reperfusion period, LADCA was re-occluded, and Evans blue dye ( $1 \mathrm{ml}$ of $\left.2 \% \mathrm{wv}^{-1}\right)$ injected i.v. to stain the area at risk. The heart was then removed and cut into four to five horizontal slices. The Evans blue solution stains the perfused myocardium, while the occluded vascular bed remains uncoloured. After removing the right ventricular wall, the area at risk and non-ischaemic myocardium were separated by following the line of demarcation between blue stained and unstained (pink/red) tissue and weighed. The area at risk was calculated and expressed as per cent of the total left ventricular weight. To distinguish between ischaemic and infarcted tissue, the area at risk was cut into small pieces and incubated with $p$ nitro-blue tetrazolium (NBT, $0.5 \mathrm{mg} \cdot \mathrm{ml}^{-1}, 20 \mathrm{~min}$ at $37^{\circ} \mathrm{C}$ ). In the presence of intact dehydrogenase enzyme systems (normal myocardium), NBT forms a dark blue formazan, whereas areas of necrosis lack dehydrogenase activity and therefore do not stain [12]. The infarct size (IS), necrotic tissue, as a function of the mass of the area at risk, and the IS as a function of the total left ventricular weight (IS/LV) were calculated according to previous studies $[13,14]$. Selected experiments were repeated monitoring the area at risk but omitting the staining procedures to provoke infarct size. Injured tissues were collected for RNA extraction and semiquantitative reverse transcription (RT)polymerase chain reaction.

In vitro ischaemia-reperfusion injury. Male Sprague-Dawley rats (4-6 months old and weighing on average $250 \mathrm{~g}$ ) were prepared for LADCA occlusion as described in the in vivo surgical procedure. The rats were then heparanised (sodium heparin, 250 IU, i.p., $10 \mathrm{~min}$ before heart excision). The hearts were rapidly excised and placed in ice-cold perfusion solution (constituents below) prior to coronary perfusion. Hearts were cannulated via the aorta and perfused retrogradely under constant flow $\left(10 \mathrm{ml} \mathrm{min}^{-1}\right)$ using a calibrated roller pump (Gilson, Miniplus-2) with a buffer solution of the following composition: $\mathrm{D}(+)$ glucose, (mmol/l) $11.1 ; \mathrm{CaCl}_{2}, 1.4 ; \mathrm{NaCl}, 118.5$; $\mathrm{NaHCO}_{3}, 25.0 ; \mathrm{MgSO}_{4}, 1.2 ; \mathrm{NaH}_{2} \mathrm{PO}_{4}, 1.2$ and $\mathrm{KCl}, 4.0$. The buffer solution was gassed with $95 \% \mathrm{O}_{2}$ and $5 \% \mathrm{CO}_{2}(\mathrm{pH} 7.4)$ and perfused at $37^{\circ} \mathrm{C}$. The coronary perfusion pressure (CPP) in the aortic line was monitored by a Statham Spectramed pressure transducer connected to a chart recorder (Grass, 79E, Quincy, Mass., USA). Air temperature was maintained by means of a heated $\left(37^{\circ} \mathrm{C}\right)$ water jacket. A total of 67 hearts were used. Some hearts were excluded for unstable preparations. A stable preparation was defined as having a sinus rate of less than 220 beats per minute or a CPP greater than $60 \mathrm{mmHg}$ between 5 and $15 \mathrm{~min}$ after beginning the perfusion. Any heart not in sinus rhythm during the study was also excluded. The remaining 50 hearts which satisfied the criteria for a stable preparation were used. Twenty hearts were perfused with the buffer solution containing D-glucose at the concentration of $11.1 \mathrm{mmol} / \mathrm{l}$ (normal glucose); and 20 were perfused with $33.3 \mathrm{mmol} / \mathrm{l}$ glucose (high glucose). Ten hearts were perfused with D-glucose $(33.3 \mathrm{mmol} / \mathrm{l})$ plus glutathione $(0.3 \mathrm{mmol} / \mathrm{l})$. To evaluate the effect of the osmotic solution per se, six hearts were perfused with a buffer solution containing D-glucose (11.1 mmol/l) plus mannitol (22.2 mmol/l).

CPP values used for statistical comparisons were calculated either as the mean of each $10 \mathrm{~min}$ value throughout the entire experiment or as the mean of the steady-state increment above baseline, if an increase of CPP was evident during an experiment.

On establishing a stable CPP (20-30 min following cannulation), LADCA was occluded as described for the in vivo experiments for $25 \mathrm{~min}$ followed by $2 \mathrm{~h}$ reperfusion. At the end of $2 \mathrm{~h}$ reperfusion period LADCA was re-occluded and Evans blue dye $(2 \%)$ infused at $1 \mathrm{ml} / \mathrm{min}$ for $1 \mathrm{~min}$. The hearts were then removed and assessed for the area at risk and infarct size as described for the in vivo study.

Selected experiments for the in vivo study were repeated monitoring the area at risk but omitting the staining procedures to determine the infarct size. Injured tissues were collected for RNA extraction and semiquantitative reverse transcription (RT)-polymerase chain reaction.

Extraction of RNA. At the end of the protocol, the heart was excised and half of each biopsy specimen was fixed in formalin, sectioned to a thickness of $5 \mu \mathrm{m}$, mounted on slides, and stained with hematoxylin and eosin. The mounted specimens were then examined for evidence of acute ischaemia and early or evolving infarction. The other half of each specimen was frozen in liquid nitrogen at $-140^{\circ} \mathrm{C}$. Portions of the frozen samples were lyophilised, and then RNA was extracted by the acid guanidinium thiocyanate-phenolchloroform technique. The recovered RNA pellet was dried under vacuum conditions for 10 to $15 \mathrm{~min}$ and then dissolved in diethyl pyrocarbonatetreated deionized distilled water. The concentration and purity of the RNA were determined by spectrophotometric analysis (Ultrospec II, Biochrom, Cambridge, UK) at 260 and $280 \mathrm{~nm}$. The samples were stored at $-80^{\circ} \mathrm{C}$ until analysed.

At the end of each experimental procedure described above, four hearts were dissected and total RNA was extracted from the whole heart using RNAzol reagent (Biotecx Lab) according to the manufacturer's protocol. Expression of HIF-1 $\alpha$ and Rac1 mRNA were measured by RT-PCR amplification [13]. Appropriate regions of the hypoxanthine-phosporybosil-transferase (HPRT) cDNA were amplified as control. Amplifications were carried out for 32 cycles, using the following conditions: $94^{\circ} \mathrm{C}$ for $1 \mathrm{~min}, 57^{\circ} \mathrm{C}$ for $1 \mathrm{~min}$ and $72^{\circ} \mathrm{C}$ for $1 \mathrm{~min}$. The primers sequences were the sequent: HIF-1 $\alpha$ Up: 5' GTG GAT ATG TCT GGG TTG AG 3', HIF-1 $\alpha$ Low: 5' ATT CTT CGC TTC TGT GTC TT 3', Rac1 Up: 5' GTG CTG AGG AGA TGG AGG TG 3', Rac1 Low: 5' GGG CTG TAA GGA AGG GAT GC 3', HPRT Up: 5' CCT GCT GGA TTA CAT TAA AGC ACT G 3', HPRT Low: 5' CTT CGT GGG GTC CTT TTC ACC AGC 3'. Each RT-PCR experiment was repeated at least three times. Amplification products were electrophoresed on $2 \%$ agarose gel in $1 \times$ TAE. Semiquantitative analysis of mRNA levels was carried out using the software associated with the Gel Doc 1000 (Biorad, Hercules, Calif., USA).

Statistical analysis. The statistical analysis was done with oneway ANOVA, followed by Duncan's multiple range test. A probability of less than $5 \%$ was considered to be statistically significant. All statistical analyses were done on IBM computers with the SOLO software package (BMDP, statistical software). All data are presented as means \pm SEM.

\section{Results}

Diabetic animals. Daily blood glucose and insulin values are shown in Fig. 1. Blood glucose averaged $6.4 \pm 0.2 \mathrm{mmol} / 1$ in basal conditions and increased to $23.1 \pm 1.9 \mathrm{mmol} / \mathrm{l} 15 \mathrm{~h}$ after STZ administration. In PGC rats, a continuous intravenous infusion of regular insulin $(1.5 \pm 0.5 \mathrm{U} /$ day) was begun and adjusted to yield blood glucose concentrations of approximately $22 \mathrm{mmol} / \mathrm{l}(396 \mathrm{mg} / \mathrm{dl})$ for 8 days. In GGC rats, the insulin dose was increased (4.1 $1 \pm 0.8 \mathrm{U} /$ day) to obtain and maintain normoglycaemia $(7.4 \pm 1.9 \mathrm{mmol} / \mathrm{l})$ for 8 days. Serum sodium and potassium concentrations and 


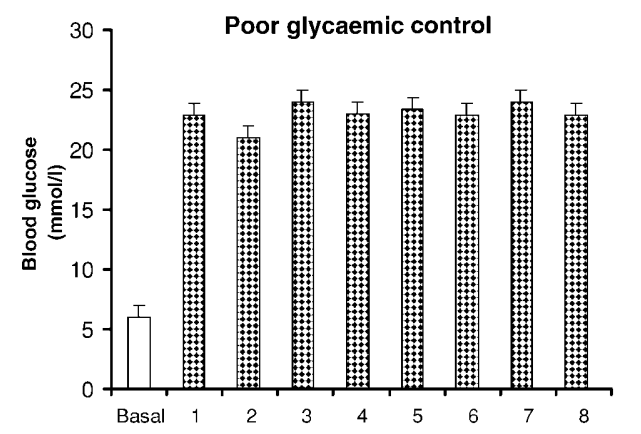

Good glycaemic control
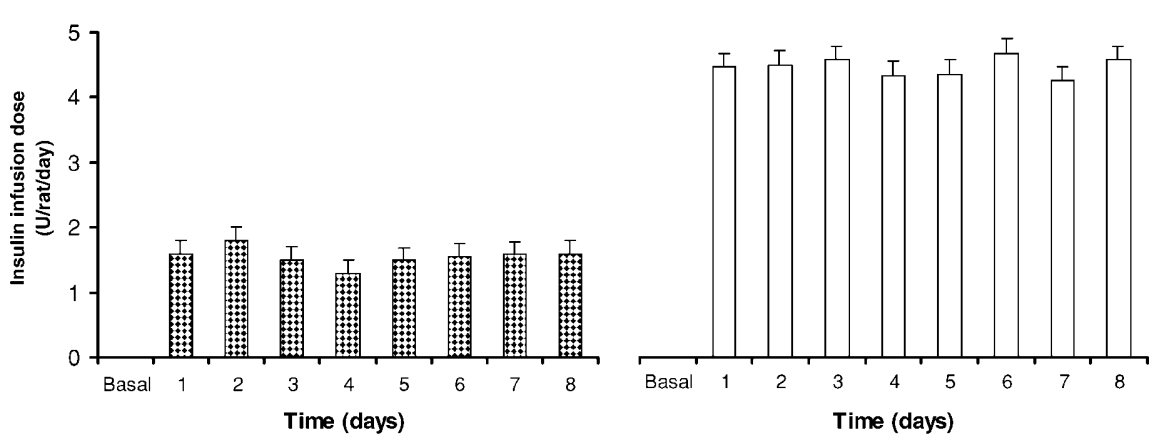

Fig. 1. Blood glucose concentrations and insulin infusion dose during the 8-day study in STZ rats

body weight did not change after STZ-treatment in PGC and GGC rats.

Haemodynamic measurements. In PGC rats, the 8-day period of hyperglycaemia resulted in an increase of MBP (from $107 \pm 2$ to $116 \pm 3 \mathrm{mmHg}, p<0.05$ ), and heart rate (from $384 \pm 8$ to $467 \pm 12$ beat $/ \mathrm{min}, p<0.05$ ), which was not evident in GGC rats. Coronary artery occlusion produced a decrease $(p<0.01)$ in MBP which was similar in all groups of rats: non-diabetic rats (from $104 \pm 2$ to $78 \pm 6 \mathrm{mmHg}, p<0.05$ ) GGC rats $(107 \pm 5$ to $82 \pm 9 \mathrm{mmHg}, p<0.05)$, PGC rats $(116 \pm 3$ to $97 \pm 9 \mathrm{mmHg}, p<0.05)$. However, recovery towards pre-occlusion values was impaired in PGC rats only $(120 \mathrm{~min}$ value $=101 \pm 7 \mathrm{mmHg}$, baseline value $=$ $116 \pm 3 \mathrm{mmHg}, p<0.05)$.

In non-diabetic hearts perfused with the control solution, CPP was $66 \pm 4 \mathrm{mmHg}$. This value increased after coronary artery occlusion and returned to basal values $2 \mathrm{~h}$ after reperfusion (coronary artery occlusion $83 \pm 9 \mathrm{mmHg}$, reperfusion $61 \pm 9 \mathrm{mmHg}$ ). Perfusion of isolated hearts with high glucose caused an increase of CPP which was evident $60 \mathrm{~min}$ after the experiment

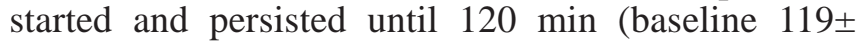
$19 \mathrm{mmHg}, p<0.001)$. Then, CPP decreased, recovering towards pre-occlusion values at $2 \mathrm{~h}$. The effect of high glucose was completely prevented by glutathione; CPP values were not different from those observed in the control group. During mannitol infusion, CPP values did not differ from those observed in nondiabetic hearts perfused with the control solution

$(67 \pm 5 \mathrm{mmHg})$. Heart rate changes were similar for all groups.

Infarct size. Occlusion of LADCA and subsequent reperfusion produced marked damage in the left ventricle. The infarct size percentage of the left ventricle was greater in the PGC rats, than in the GGC rats $(p<0.05)$ and non-diabetic control rats $(p<0.05)$ (Fig. 2). In isolated hearts, high glucose produced an increase in infarct size percentage of the left ventricle compared with the control and glutathione groups $(p<0.05)$ (Fig. 2). There was no significant difference in the area at risk of left ventricle among groups, both in vivo and in vitro (Fig. 2). Myocardial infarct size was $57 \pm 2.3 \%$ of the area at risk in PGC rats, a value which was higher than that recorded in the GGC rats $(48.5 \pm 1.1, p<0.01)$ and in non-diabetic rats $(48 \pm 2.1$, $p<0.02)$. In an isolated heart perfused with high glucose, myocardial infarct size was $58 \pm 2.1 \%$ of the area at risk; this value was higher than the one observed in hearts perfused with normal glucose concentration $(39 \pm 3 \%, p<0.01)$, as well as in heart perfused with high glucose plus glutathione $(41 \pm 4 \%, \quad p<0.02)$ (Fig. 2). There was a linear relation between infarct size of the area at risk and plasma glucose concentrations in all diabetic rats $(r=0.89 ; p<0.001)$. Infarct size of isolated hearts was not different between control rats perfused with or without glutathione and during mannitol infusion. There was no relation between infarct size and MBP changes during occlusion and reperfusion.

Cardiac HIF-1 $\alpha$ expression. In basal conditions, cardiac HIF- $1 \alpha$ mRNA expression was not appreciable in non-diabetic rats and in GGC rats. HIF- $1 \alpha$ expression was already present in hearts after 8 days of poor 

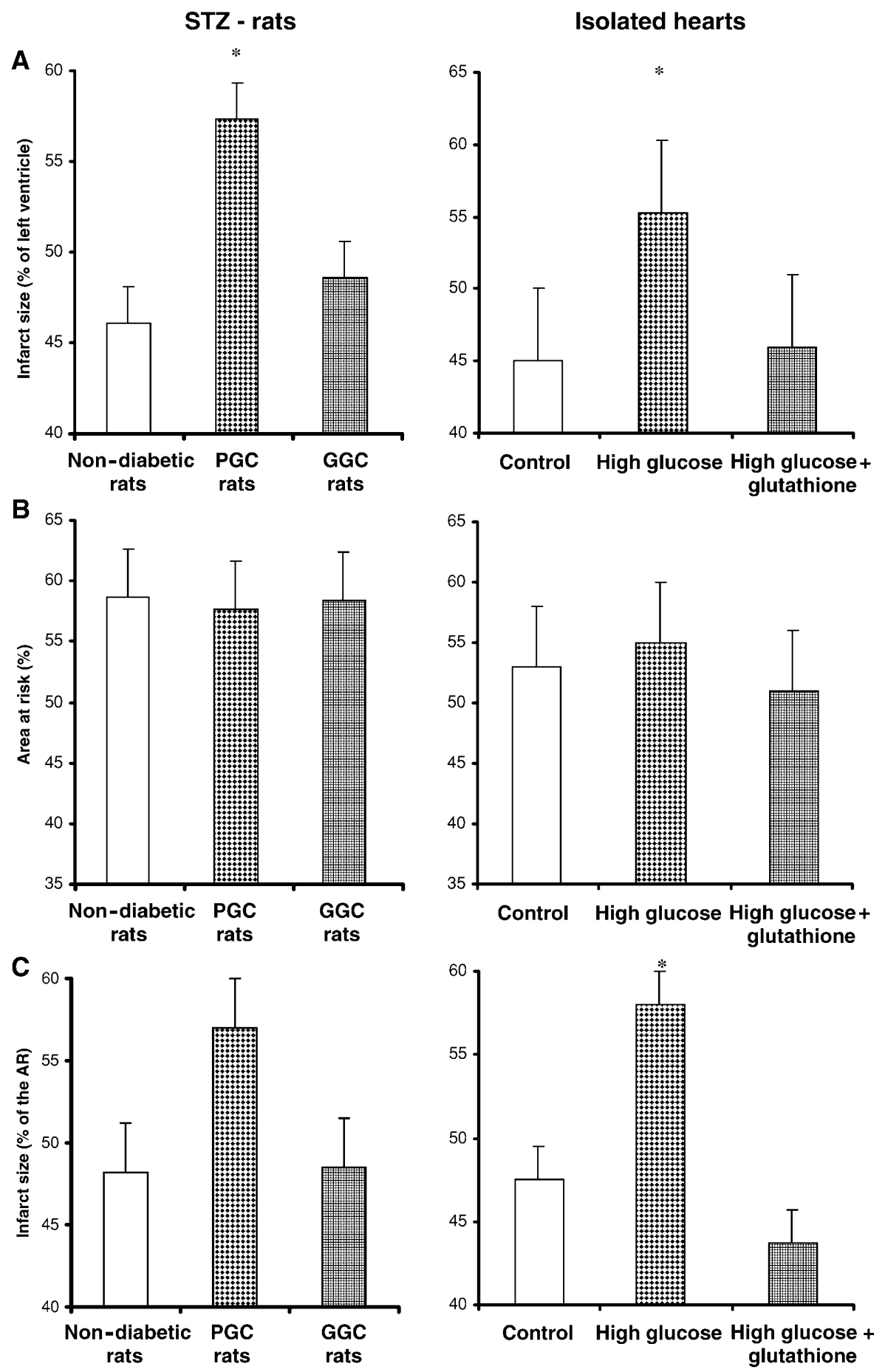

Fig. 2. Histograms illustrating myocardial infarct size expressed as a percentage of left ventricle $(\mathbf{A})$; myocardial area at risk (AR) expressed as a percentage of left ventricle (B); myocardial infarct size expressed as a percentage of the area at risk (C). *Significantly $(p<0.05)$ different from non-diabetic rats and control hearts. $G G C$, good glycaemic control; PGC, poor glycaemic control

glycaemic control. HIF- $1 \alpha$ expression increased after ischaemia in non-diabetic rats, reaching a value of $762 \pm 86 \%$ from the baseline $(p<0.001)$. In contrast, the percent increase from the baseline of HIF- $1 \alpha$ m RNA expression after ischaemia in PGC rats was only $52.3 \pm 16 \%$ above the baseline, that is $6.8 \pm 6 \%$ of the incremental expression seen in non-diabetic rats $(p<0.001)$. In GGC rats, HIF-1 $\alpha$ increased after ischaemia was higher $(p<0.001)$ than that of PGG rats, but still lower than non-diabetic rats $(56 \pm 10 \%$ of the nondiabetic group, $p<0.01$ ) (Fig. 3). Before ischaemia, expression of HIF-1 $\alpha$ in isolated hearts perfused with 
STZ - rats

A

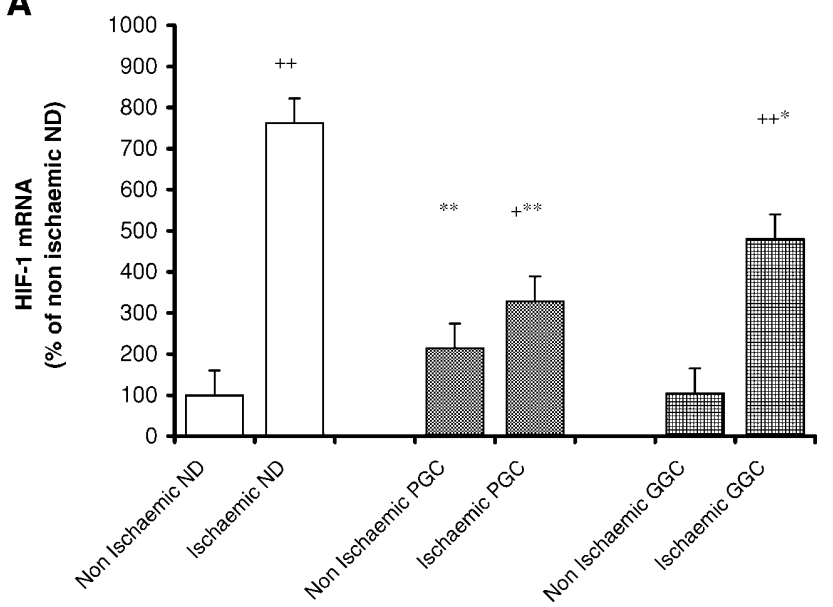

B

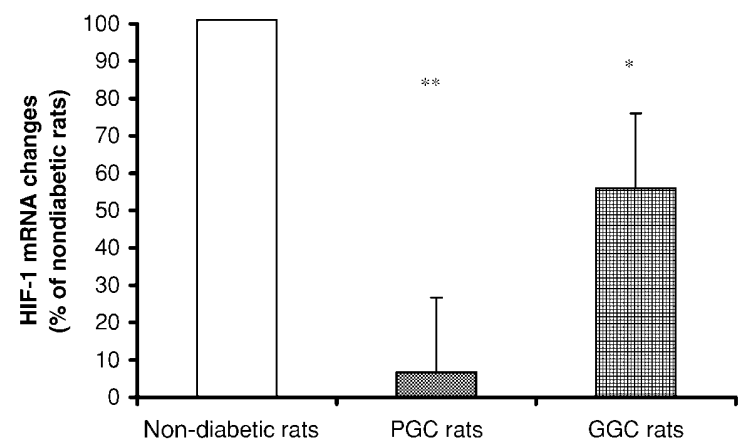

Fig. 3A, B. Histograms illustrating mRNA HIF-1 $\alpha$ expression in STZ rats. A mRNA expression for HIF- $1 \alpha$ as percent of nonischaemic non-diabetic rats (non-ischaemic ND), in ischaemia non-diabetic rats (ischaemic ND), non-ischaemic poor glycaemic control rats (non-ischaemic PGC), in ischaemic poor glycaemic control rats (ischaemic PGC), in non-ischaemic good glycaemic control rats (non-ischaemic GGC) and in ischaemic good glycaemic control rats (ischaemic GGC). B mRNA HIF$1 \alpha$ expression variations after ischaemia-reperfusion expressed as percent of changes evoked by ischaemia in non-diabetic rats. ${ }^{*} p<0.05,{ }^{*} p<0.001$ vs non-diabetic rats. $+p<0.05,++p<0.001$ different from sham values of each group

normal glucose $(10 \mathrm{mmol} / \mathrm{l})$ was not appreciable, but was present in isolated heart perfused with high glucose $(33 \mathrm{mmol} / \mathrm{l})$. Following ischaemia, expression of HIF- $1 \alpha$ in hearts perfused with high glucose concentration was lower than that recorded in hearts perfused with normal glucose $(p<0.001)$ (Fig. 4). The effects of high glucose were prevented by glutathione, both in basal conditions and in response to ischaemia (Fig. 4).

Cardiac Rac1 expression. Rac1 expression was not appreciable in basal conditions, both in non-diabetic rats and in GGC rats. Rac1 expression was already present in hearts of STZ-diabetic rats after 8 days of poor glycaemic control. After coronary artery occlusion, a rise in Rac1 expression $(p<0.001)$ was observed in non-diabetic rats. In comparison to non-diabetic rats, Rac1 expression was lowest in PGC rats
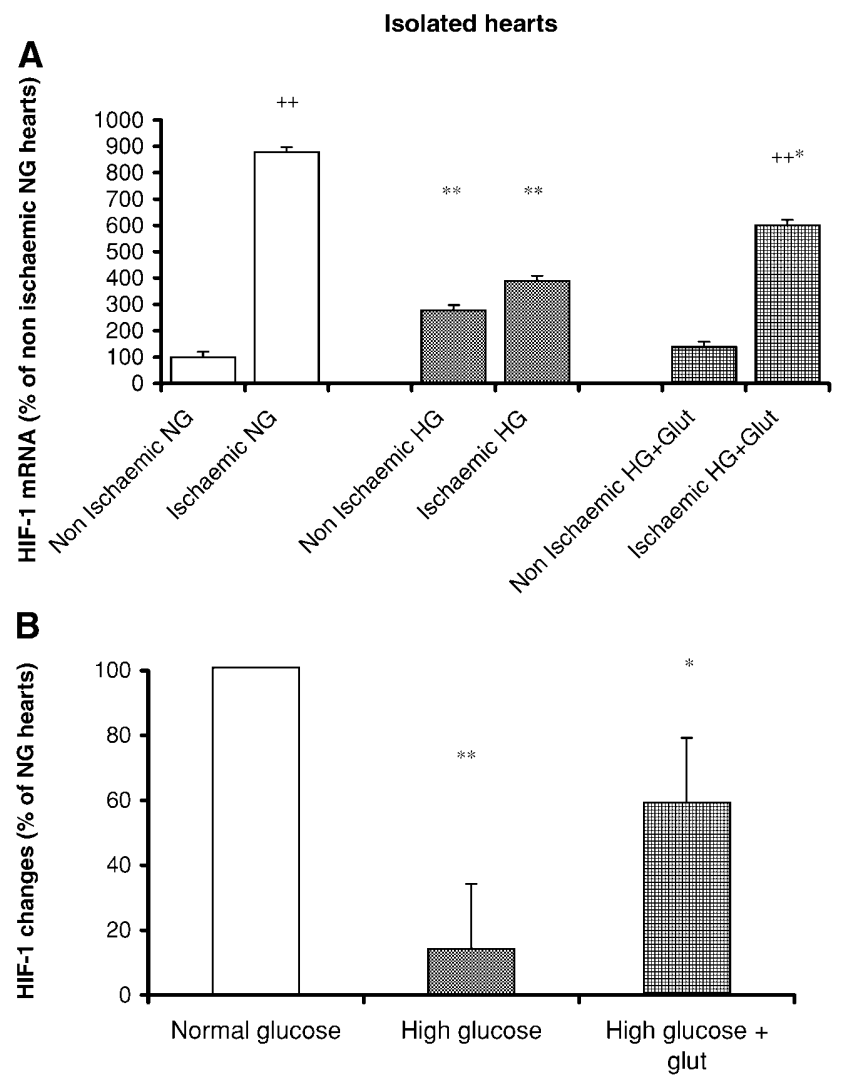

Fig. 4A, B. Histograms illustrating mRNA HIF-1 $\alpha$ expression in isolated hearts. A mRNA expression for HIF- $1 \alpha$ as percent of non-ischaemic normal glucose hearts (non-ischaemic NG), in ischaemic normal glucose hearts (ischaemic NG), in non-ischaemic high glucose group (non-ischaemic $\mathrm{HG}$ ), in ischaemic high glucose hearts (ischaemic $\mathrm{HG}$ ), in non-ischaemic high glucose + glutathione group (non-ischaemic HG + GLUT) and in ischaemic high glucose + glutathione hearts (ischaemic HG + GLUT). B mRNA HIF-1 $\alpha$ expression variations after ischaemia-reperfusion expressed as percent of changes evoked by ischaemia in normal glucose hearts. ${ }^{*} p<0.05, * * p<0.001$ vs control group values; $+p<0.001$ different from sham values of each group

and intermediate in GGC rats (Fig. 5). Before ischaemia, expression of Rac1 in hearts perfused with normal glucose was not appreciable, but was present in hearts perfused with high glucose. After ischaemia, Rac1 expression in hearts perfused with high glucose was lower than that observed in hearts perfused with normal glucose $(p<0.001)$. The effect of high glucose was prevented by glutathione; Rac1 expression was not different from that observed in control hearts, both in basal conditions and in response to ischaemia (Fig. 6).

\section{Discussion}

One important finding of this study is the difference in myocardial infarct size between diabetic rats in good 
STZ - rats
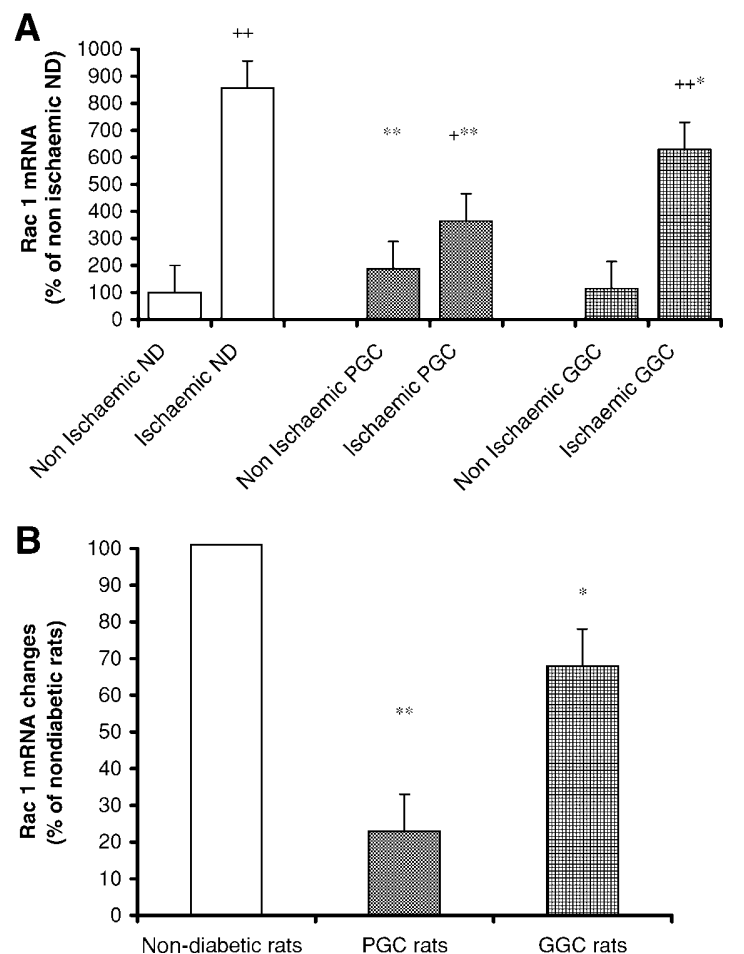

Fig. 5A, B. Histograms illustrating mRNA Rac1 expression in STZ rats. A mRNA expression for Rac1 as percent of nonischaemic non-diabetic rats (non-ischaemic ND), in ischaemic non-diabetic rats (ischaemic, ND), in non-ischaemic poor glycaemic control rats (non-ischaemic PGC), in ischaemic poor glycaemic control rats (ischaemic PGC), in non-ischaemic good glycaemic control rats (non-ischaemic GGC) and in ischaemic good glycaemic control rats (ischaemic GGC). B mRNA Rac1 expression variations after ischaemia-reperfusion expressed as percent of changes evoked by ischaemia in non-diabetic rats. $* p<0.05, * * p<0.001$ vs non-diabetic rats. $+p<0.05$, $++p<0.001$ different from sham values of each group

glycaemic control and diabetic rats in poor glycaemic control. Eight days of poorly controlled diabetes were enough to cause an increase in infarct size, which was not different from that observed in non-diabetic control rats when blood glucose was fully normalized by insulin infusion.

Previous studies investigating the extent of ischaemic injury in diabetic myocardium have been controversial despite overwhelming clinical evidence that the diabetic heart is highly sensitive to such injury $[14,15,16,17]$. Differences in the severity (degree of hyperglycaemia) and chronicity of the diabetic state [18], as well as the experimental condition and model used [17], could explain the disparity in experimental findings. The streptozotocin model which we used has been shown to reliably produce diabetes in rats with minimal systemic toxicity [19] and is characterised by substantial increases in fasting blood glucose concentration (15-24 $\mathrm{mmol} / \mathrm{l})$ and marked insulinopenia. Apart from the obvious difference in the degree of

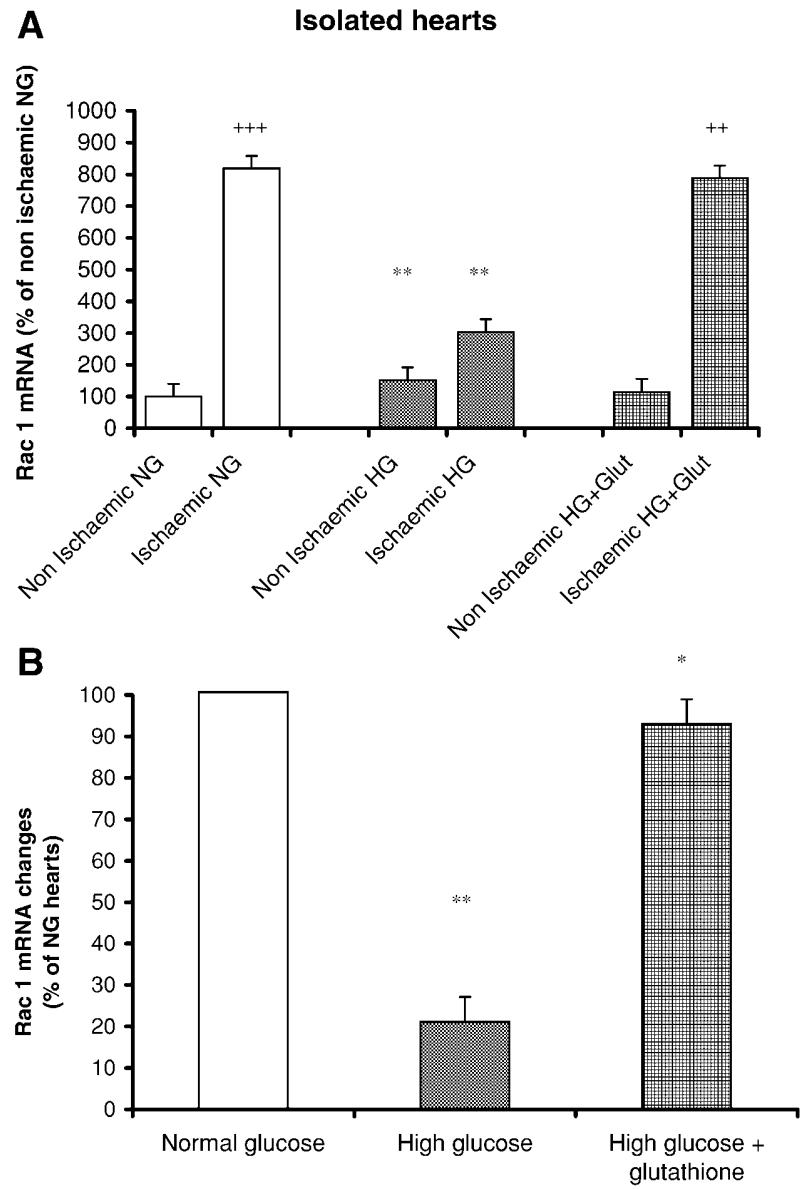

Fig. 6A, B. Histograms illustrating mRNA Rac1 expression in isolated hearts. A mRNA expression for Rac1 as percent of non-ischaemic normal glucose hearts (non-ischaemic NG), in ischaemic normal glucose hearts (ischaemic NG), in non-ischaemic high glucose hearts (non-ischaemic HG), in ischaemic high glucose hearts (ischaemic HG), in non-ischaemic high glucose + glutathione hearts (non-ischaemic HG + GLUT) and in ischaemic high glucose + glutathione hearts (ischaemic $\mathrm{HG}+$ GLUT). B mRNA Rac1 expression variations after ischaemiareperfusion expressed as percent of changes evoked by ischaemia in control group. ${ }^{*} p<0.05, * * p<0.001$ vs control group values; $+p<0.001$ different from sham values of each group

glycaemic control, in theory other factors might have accounted for the difference in infarct size between PGC rats and GGC rats. A perturbation of serum electrolytes seems to be excluded, as serum sodium and potassium concentrations did not change 8 days after STZ-induced diabetes. Moreover, stimulation of electrolyte transport systems in the kidney, occurring in short-term treatment with STZ, could prevent excessive modifications of serum electrolytes [20]. An increase of circulating NEFA concentrations [21], as well as altered platelet [22] and fibrinolytic function [23], mostly as a consequence of STZ-induced hypoinsulinaemia, might also have contributed to the increase of infarct size seen in PGC rats.

In order to dissect the effect of hyperglycaemia itself independent of the diabetic state, we repeated 
ischaemia-reperfusion experiments in isolated working hearts perfused with high glucose concentration. Our data suggest that infarct size is a primary consequence of hyperglycaemia, since high glucose concentration in the perfusion medium of isolated hearts produced an infarct size similar to that observed in STZ diabetic rats in poor glycaemic control. Our findings showing that both sustained hyperglycaemia in vivo and high glucose infusion in vitro increase infarct size in rats are in line with the mounting clinical evidence that hyperglycaemia could augment the risk of myocardial infarction in diabetic and non-diabetic subjects [24].

The mechanisms by which hyperglycaemia could influence infarct size are not clear. Although there is some controversy about the protective effect of antioxidants in the context of ischaemia and reperfusion [25], the ability of glutathione to contrast, at least in part, the amplifying effect of hyperglycaemia on infarct size suggests that prevailing oxidative stress could be an important feature of glucose-induced oxidant and antioxidant imbalance [17]. This could be an explanation for the increased susceptibility of diabetic rats to hypoxic and ischaemic injuries. This seems in line with evidence that an increased susceptibility to injury occurs when the glutathione content in the ischaemic myocardium becomes depleted [26] and that glutathione-knockout mice are more susceptible to ischaemia reperfusion injury [27].

Another finding of this study was the impairment in HIF- $1 \alpha$ expression associated with increased infarct size in STZ diabetic rats in poor glycaemic control, as well as in isolated hearts perfused with high glucose. This indicates that glucose can interfere with transcriptional activation of angiogenesis. To survive periods of stress and ischaemia, the human heart has developed mechanisms to adapt to changes in its environment. One of these mechanisms is the ability to promote growth of new blood vessels into ischaemic areas, thus limiting regions of impairment and ultimately preserving myocardial function [28]. One of the first genes up-regulated by hypoxia is the gene encoding HIF-1 protein composed of two distinct peptides [6]. Expression of the gene for HIF- $1 \alpha$ is exquisitely sensitive to the onset of cellular hypoxic conditions, making it one of the earliest effectors of the response to ischaemia [29]. By promoting angiogenesis and vascular remodelling, HIF-1 $\alpha$ contributes to limitation of infarct size; therefore, any factor that limits HIF- $1 \alpha$ expression in response to ischaemia could in theory extend infarct size and accelerate heart failure. Of interest, both of these conditions are typical of the diabetic state in humans [30, 31]. Moreover, sections from autopsied hearts evidenced that ischaemiainduced angiogenesis is impaired in hearts of diabetic patients compared with infarcted hearts of normoglycaemic non-diabetic patients [32].

Various $\mathrm{O}_{2}$-sensing mechanisms have been proposed to mediate the HIF-1 $\alpha$ response to hypoxia
[33]. The generation of reactive oxygen species (ROS) by a flavoprotein-containing $\mathrm{NAD}(\mathrm{P}) \mathrm{H}$ oxidase or by mitochondria are thought to be involved $[34,35]$. In addition to changes in cellular redox, hypoxia signal transduction might also require kinase and phosphatase activity [36]. Experimental evidence has focused on the Rho family-small GTPase Rac1 as a potential intermediate in the hypoxia signal-transduction pathway. Rac1 regulates assembly of the active $\mathrm{NAD}(\mathrm{P}) \mathrm{H}$ oxidase complex and is recognised as a critical determinant of intracellular redox status [37]. Recent data indicate that Rac1 is required for the induction of HIF-1 $\alpha$ protein expression and HIF- $1 \alpha$-dependent gene transcription in response to hypoxia, although Rac1-independent signals are also required for HIF-1 $\alpha$ activation under non-hypoxic conditions [11]. We observed that ischaemia-induced Rac1 expression was reduced in diabetic rats in poor glycaemic control compared with non-diabetic rats and diabetic rats in good glycaemic control. These findings were paralleled by the evidence that high glucose concentration in the perfusion medium of isolated working hearts produced a reduction in Rac1 expression in response to ischaemia. The ability of exogenous glutathione to normalise both Rac1 and HIF-1 $\alpha$ expression brought about by high glucose in isolated hearts suggests that prevailing oxidative stress could be a key regulatory component in mediating HIF- $1 \alpha$ response to ischaemia, with the help of Rac1. The evidence that diabetes could influence Rac1 expression is scarce. In one study, the contents of Rac1 protein in enterocytes were found markedly decreased in streptozotocininduced diabetic rats and restored by short-term treatment with insulin [38].

Our last finding was that basal HIF-1 expression was increased in hearts of diabetic rats as well as in isolated non-diabetic rat hearts perfused with high glucose, suggesting a pseudohypoxic state. In many tissues, hyperglycaemia-induced metabolic imbalances increase the cytosolic ratio of free NADH:NAD+ (despite normal tissue $\mathrm{PO}_{2}$ ) that results in pseudohypoxia [39]. On the contrary, in hypoxic and ischaemic myocardium, the redox imbalance results from impaired mitochondrial oxidation of $\mathrm{NADH}$ to NAD+ because of decreased $\mathrm{PO}_{2}$. Although the mechanisms responsible for the dichotomic effect of hyperglycaemia on HIF-1 $\alpha$ expression are not disclosed by our study, hypoxic or ischaemic episodes that increase HIF- $1 \alpha$ in non-diabetic rats when superimposed on preexisting hyperglycaemia-mediated pseudohypoxia, could possibly result in the impairment of the burst of HIF-1 $\alpha$ expression. Interestingly, nitric oxide donors induce HIF- $1 \alpha$ expression and activity in cultured myocardial cells [40] and hyperglycaemic pseudohypoxia is associated with increased production of nitric oxide [39]. Nevertheless, the huge generation of ROS following ischaemia reperfusion injury might quench nitric oxide, possibly via peroxy- 
nitrite formation [41], limiting a stimulus of HIF-1 $\alpha$. Apart from these speculations, the finding that glutathione prevents the changes in myocardial tissue of both diabetic animals and isolated rat hearts perfused with high glucose clearly suggests an important role of raised ROS production in these responses.

In conclusion, the extent of myocardial infarct size in diabetic hearts and non-diabetic hearts perfused with high glucose is greater than their normoglycaemic counterparts. Defective response of the transcriptional factor HIF- $1 \alpha$ to ischaemia is partially restored by normoglycaemia or glutathione, suggesting a role for ROS brought about by high glucose concentrations. The reduced HIF- $1 \alpha$ response to ischaemia, strictly related to hyperglycaemia, could interfere with the promotion of angiogenesis and vascular remodelling in the ischaemic myocardium. Whether this plays a part in the poor prognosis of the diabetic heart awaits further elucidations.

\section{References}

1. Cruikshank N (1931) Coronary thrombosis and myocardial infarction, with glycosuria. BMJ 1:618-619

2. Capes SE, Hunt D, Malmberg K, Gerstein HC (2000) Stress hyperglycaemia and increased risk of death after myocardial infarction in patients with and without diabetes: a systematic overview. Lancet 355:773-778

3. Yudkin IS, Oswald GA (1987) Hyperglycaemia, diabetes and myocardial infarction. Diabet Med 4:13-18

4. Malmberg K, Ryden L, Efendie S et al. (1995) On behalf of the DIGAMI Study Group. A randomised trial of insulinglucose infusion followed by subcutaneous insulin treatment in diabetic patients with acute myocardial infarction: effects on mortality it 1 year. J Am Coll Cardiol 26:57-65

5. Ladoux A, Frelin C (1993) Hypoxia is a strong inducer of vascular endothelial growth factor mRNA expression in the heart. Biochem Biophys Res Commun 195:1005-1010

6. Semenza CL (1998) Hypoxia inducible factor 1: master regulator of $\mathrm{O}_{2}$, hemostasis. Curr Opin Genet Dev 8:588-394

7. Semenza CL, Wang CL (1992) A nuclear factor induced by hypoxia via dc novo protein synthesis binds to the human erythropoietin gene enhancer at a site required for transcriptional activation. Mol Cell Biol 12:5447-5454

8. Ozaki H, Yu AY, Della N et al. (1999) Hypoxia inducible factor is increased in ischemic retina: temporal and spatial correlation with VEGF expression. Invest Ophthalmol Vis Sci 40:182-189

9. Yu AY, Frid MG, Shimoda LA, Wiener CM, Stenmark K, Semenza CL (1998) Temporal, spatial, and oxygen-regulated expression of hypoxia-inducible factor-1 in the lung. Am J Physiol 273:L818-L826

10. Lee HL, Wolf PL, Escudero R, Deutsch R, Jamesion SW, Thistlethwaite PA (2000) Early expression of angiogenesis factors in acute myocardial ischaemia and infarction. $\mathrm{N}$ Engl Med 342:626-633

11. Hirota K, Semenza GL (2001) Rac1 activity is required for the activation of hypoxia-inducible factor 1 . J Biol Chem 276:21166-21172

12. D'Amico M, Di Filippo C, Solito E et al. (2000) Lipocortin 1 reduces myocardial ischaemia-reperfusion injury by affecting local leukocyte recruitment. FASEB J 14:1867-1869
13. Galderisi U, Cipollaro M, Melone MA et al. (1996) Myotonic dystrophy: antisense oligonucleotide inhibition of DMPK gene expression in vitro. Biochem Biophys Res Commun 221:750-754

14. Kersten JR, Toller WG, Gross ER, Pagel PS, Warltier DC (2000) Diabetes abolishes ischemic preconditioning: role of glucose, insulin, and osmolality. Am J Physiol 278:H1218H1224

15. Hadour G, Ferrera R, Sebbag L, Forrat R, Delaye J, Lorgeril M (1998) Improved myocardial tolerance to ischaemia in the diabetic rabbit. J Mol Cell Cardiol 30:1869-1875

16. Liu Y, Thornton JD, Cohen MV, Downey JM, Schaffer SW (1993) Streptozotocin-induced non-insulin-dependent diabetes protects the heart from infarction. Circulation 88:1273-1278

17. Paulson DJ (1997) The diabetic heart is more sensitive to ischemic injury. Cardiovasc Res 34:104-112

18. Tosaki A, Engelman DT, Engelman RM, Das DK (1996) The evolution of diabetic response to ischaemia/reperfusion and preconditioning in isolated working rat hearts. Cardiovasc Res 31:526-536

19. Anderson HR, Stitt AW, Gardiner TA, Lloyd SJ, Archer DB (1993) Induction of alloxan/streptozotocin diabetes in dogs: a revised experimental technique. Lab Anim 27:281-285

20. Tomlison KC, Gardiner SM, Hebden A, Bennett T (1992) Functional consequences of streptozotocin-induced diabetes mellitus, with particular reference to the cardiovascular system. Pharmacol Rev 44:103-150

21. Oliver M, Opie LH (1994) Effects of glucose and fatty acids on myocardial ischaemia and arrhythmias. Lancet 343:155-158

22. Winocour PD (1992) Platelet abnormalities in diabetes mellitus. Diabetes 41 [Suppl 2]:26-31

23. Gray RP, Yudkin JS, Patterson DL (1993) Plasminogen activator inhibitor: a risk factor for myocardial infarction in diabetic patients. Br Heart J 69:228-232

24. Coutinho M, Gerstein MC, Wang Y, Yusuf S (1999) The relationship between glucose and incident cardiovascular events: a metaregression analysis of published data from 20 studies of 95,783 individuals followed for 12.4 years. Diabetes Care 22:233-240

25. Lefer DJ, Granger DN (2000) Oxidative stress and cardiac disease. Am J Med 109:315-323

26. Singh A, Lee KJ, Lee CY, Goldfarb RD, Tsan MF (1989) Relation between myocardial glutathione content and extent of ischaemia-reperfusion injury. Circulation 80:1795-1804

27. Yoshida T, Maulik N, Engelman RM et al. (1997) Glutathione peroxidase knockout mice are susceptible to myocardial ischaemia reperfusion injury. Circulation 4 [Suppl 2]:216-220

28. Sabia PJ, Powers ER, Ragosta M, Sarembock IJ, Burwell LR, Kaul S (1992) An association between collateral blood flow and myocardial viability in patients with recent myocardial infarction. N Engl J Med 7:1825-1831

29. Jiang BH, Zheng JZ, Leung SW, Roe R, Semenza GL (1997) Transactivation and inhibitory domains of hypoxiainducible factor la: modulation of transcriptional activity by oxygen tension. J Biol Chem 272:19253-19260

30. O'Sullivan JJ, Conroy RM, Robinson K, Hickey N, Mulcahy R (1991) In hospital prognosis of patients with fasting hyperglycaemia after first myocardial infarction. Diabetes Care 14:758-760

31. Iribarren C, Karter AJ, Go AS et al. (2001) Glycaemic control and heart failure among adult patients with diabetes. Circulation 103:2668-2673 
32. Yarom R, Zirkin H, Stammler G, Rose AG (1992) Human coronary microvessels in diabetes and ischaemia. Morphometric study of autopsy material. J Pathol 166:265-270

33. Semenza GL (1999) Regulation of mammalian O2 homeostasis by hypoxia-inducible factor 1 . Annu Rev Cell Dev Biol 15:551-578

34. Genius J, Fandrey J (2000) Nitric oxide affects the production of reactive oxygen species in hepatoma cells: implications for the process of oxygen sensing. Free Radic Biol Med 29:515-521

35. Chandel NS, Maltepe E, Goldwasser E, Mathieu CE, Simon MC, Schumacker PT (1998) Mitochondrial reactive oxygen species trigger hypoxia-induced transcription. Proc Natl Acad Sci U S A 95:11715-11720

36. Wang GL, Jiang BH, Semenza GL (1995) Effect of protein kinase and phosphatase inhibitors on expression of hypoxia-inducible factor 1. Biochem Biophys Res Commun 216:669-675
37. Grizot S, Faure J, Fieschi F, Vignais PV, Dagher MC, Pebay-Peyroula E (2001) Crystal structure of the Rac1RhoGDI complex involved in NADPH oxidase activation. Biochemistry. 40:10007-10013

38. Chono E, Kurokawa T, Oda C, Kawasaki K, Yamamoto T, Ishibashi S (1997) Expression of rac1 protein in the cryptvillus axis of rat small intestine: in reference to insulin action. Biochem Biophys Res Commun 233:455-458

39. Williamson JR, Chang K, Frangos M et al. (1993) Hyperglycaemic pseudohypoxia and diabetic complications. Diabetes 42:801-813

40. Kimura H, Kimura H, Weisz A et al. (2000) Hypoxia response element of the human vascular endothelial growth factor gene mediates transcriptional regulation by nitric oxide: control of hypoxia-inducible factor 1 activity by nitric oxide. Blood 95:189-197

41. Frustaci A, Kajstura J, Chimenti C et al. (2000) Myocardial cell death in human diabetes. Circ Res 87:1123-1132 